\title{
Shear-bond behavior of fiber reinforced polymer (FRP) rods and sheets
}

\author{
Aylie $\mathrm{Han}^{1, *}$, Buntara S. Gan ${ }^{2}$, and Agung Budipriyanto ${ }^{3}$ \\ ${ }^{1}$ Structural and Material Laboratory, Diponegoro University, Tembalang, Semarang, Indonesia \\ ${ }^{2}$ Nihon University, College of Engineering, Department of Architecture, Koriyama, Japan \\ ${ }^{3}$ Department of Civil Infrastructure Engineering, Institut Teknologi Sepuluh Nopember, Surabaya, \\ Indonesia
}

\begin{abstract}
The use of external reinforcement has gained an increasingly major position due to the adjustment in earthquake standards, mandating a significant improvement in the section's moment capacity. Studies on the behavior and enhancement contributed by FRP sheets demonstrated that its effectiveness was a direct function of the shear-bond strength. A prominent contributing factor was the response of the interface between the sheets and the epoxy resin, and the interface between the epoxy resin to the concrete surface. Recently, FRP rods were produced. These rods which are 8 and 10 millimeters in diameter offer ease in use, and simplicity in the application procedure. This study looked into the shear-bond behavior of FRP rods as compared to sheets. Direct tensile stresses were applied to test the shearbond between the sheets and rods, attached to a $35 \mathrm{MPa}$ concrete surface. The failure behavior of the bond was also monitored. Additionally, the effectiveness of the embedded depth of the FRP rods relative to the concrete surface was also analyzed.
\end{abstract}

Keywords: reinforced concrete strengthening, fiber reinforced polymer rod, bond strength

\section{Introduction}

The use of external reinforcement for reinforced concrete structures is especially useful when dealing with special cases where an enhancement in section capacity is required. While in the past these external reinforcements were predominantly performed using steel bars or steel plates, it has now become clear that the introduction of Fiber Reinforced Polymer (FRP) provides a much better alternative in improving a section's performance. FRP elements are not only versatile concerning corrosion control and fatigue resistance, but the material can also withstand very high stresses. The first generation of FRP was introduced in the late 1990s and mostly consisted of woven sheets or bars. The evaluation of FRP use in Europe was outlined by Taerwe and Matthys [1], while in the USA FRP tendons were used to utilize prestressed concrete sections [2]. One of the challenging perspectives was the bond aspect for the pre-tension system and the anchorage-slip for post-tension members. So, from the beginning of its use, the numerous advantages were accompanied by bond issues.

\footnotetext{
*Corresponding author: hanaylie@live.undip.ac.id
} 
From the introduction of FRP rods to be used as external reinforcement rose an interesting topic for continuing investigation in the bond behavior of FRP. Contradictory to the FRP sheets, the position of FRP rods relative to the concrete surface became a variable. Although the code and the producer mandated a 1.5 diameter rod embedment depth, in reality, factors such as the configuration of stirrups and concrete cover thickness restricted the maximum embedment depth into the concrete. A study was conducted to evaluate the effect of the relative position of FRP rods to the concrete surface [3]. It was shown that the bond behavior of FRP rods was a direct function to the relative distance of the rods to the concrete surface. This paper analyses and compares the effectiveness and bond behavior of the two systems: the FRP sheets and FRP rods.

\section{Research methodology and experimental work}

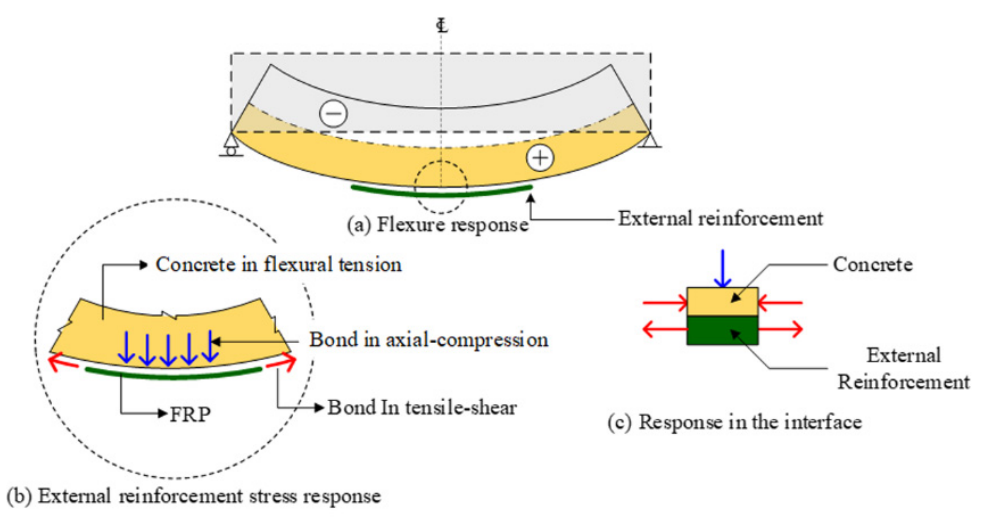

Fig. 1. Stress responses in the interface of external reinforcement in flexure.

In reinforced concrete, the bond is crucially important since through this media the tensile stresses from the concrete are transferred to the reinforcement. The mechanism is straightforward, and the bond behavior is generally differentiated in the response perpendicular, and parallel to the load direction (Fig. 1a). In flexure, the bond response perpendicular to the line of loading becomes less influential, due to its compression nature (Fig. 1b). The tensile-shear bond response thus will govern the failure mode and determine the strength of the composite (Fig. 1c). All FRP reinforcements are attached to the concrete with an epoxy resin that chemically materializes an interface between the concrete and the FRP. This resin forms the compatibility when strains are induced in the interface.

The failure mechanisms of FRP external reinforced members are distinguished into four modes: failure in the interface between the epoxy and the concrete, bond-loss between the FRP and the epoxy, tensile failure in the FRP, and tensile-shear failure in the concrete. To optimize the external reinforcement, this last failure mechanism must be the target. When the FRP ruptures in tension, the failure mode can be shifted by increasing the FRP material strength or the reinforcement area. The bond between the concrete and the epoxy is a function of the concrete strength and chemical bonding between the two materials. The most sensitive is the debonding between the FRP and the epoxy resin. Research work on FRP sheets [4] has proven that a well-designed surface treatment prior to placement of the epoxy could significantly alter the failure mechanism from debonding to concrete fracture.

The tests were designed to measure the force at failure in direct tensile-shear [5-7]. The sheets and rods were attached symmetrically to two blocks of concrete having a cylindrical compression strength $f^{\prime}{ }_{c}$ of 55.6 MPa. This symmetrical configuration ensured an axial load to be applied to the pull-off bars, resulting in uniform stress in the interface area. The test 
specimens were designed to fail due concrete tension-shear, by controlling the attached bonded length of the FRP to the concrete. Stress concentrations on the edges of the concrete blocks were anticipated by creating an unbonded zone [8].

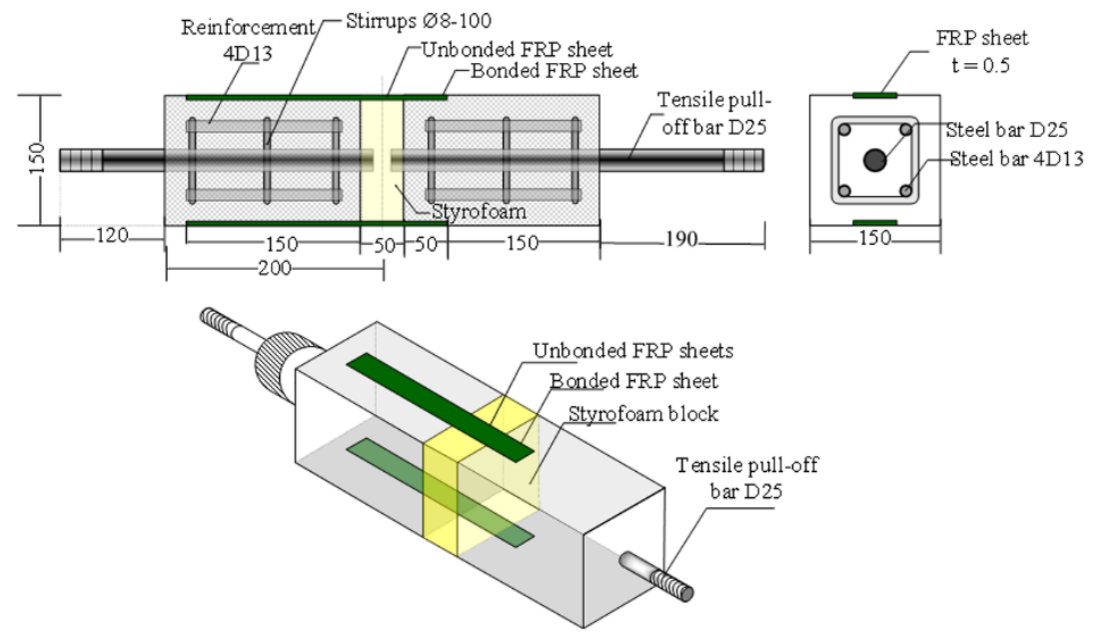

Fig. 2. Specimen assemblage for FRP sheets testing [4].

At the first stage, the FRP sheet bond behavior was tested. Two tensile pull-off bars were placed in the center of the concrete section. In between the two concrete blocks, a Styrofoam divider with a hole was affixed to control the centricity of the two bars' axes (Fig. 2). When at the age of 28 days the cast was removed and the two tensile bars was secured within the jaws of the universal testing machine (UTM), the Styrofoam was carefully taken away. The method was time-consuming, and observations on the position of the axes suggested that small eccentricities were present. The thin FRP sheets measuring only $0.5 \mathrm{~mm}$ in thickness were also very sensitive to movement, multiplying the risk of eccentricity during testing. The presence of eccentricity was confirmed when twisting of the two concrete blocks at early loading stages was detected. Furthermore, closer analyses of the failure pattern in the concrete suggested a non-uniform failure for the opposite test areas. In combination with the thin sheets, a low stiffness of the assemblage resulted, yielding in rupture of the sheets in the unbonded as well as bonded zones.

The most concerning aspect of the set-up was the eccentricity of the pull-off bars. The presence of Styrofoam did not guaranty a stable position of the bars during casting and concrete compacting. To overcome this weakness, a new set-up method was introduced for the FRP rod experiment. The pull-off bar was cast as one piece, stretching from the very left to the right end of the casting. The casts were prepared as two separate boxes having a distance of $20 \mathrm{~mm}$ apart, with a centric hole on both ends for the bar.

The stiffness of the cast and the integrity of the one-piece pull-off bar ensured a much better performance during testing. At the age of 28 days, the casts were removed, and the specimens arranged in the UTM. When the jaws are securely fastened, the center section of the bar was cut with a welding torch, while cold packs were placed surrounding the bar in the $20 \mathrm{~mm}$ gap between the two concrete blocks. This method was chosen to minimize the negative temperature rise effect to the concrete and especially the ITZ bond [3]. The test setup of the FRP rod is seen in Fig. 3. 


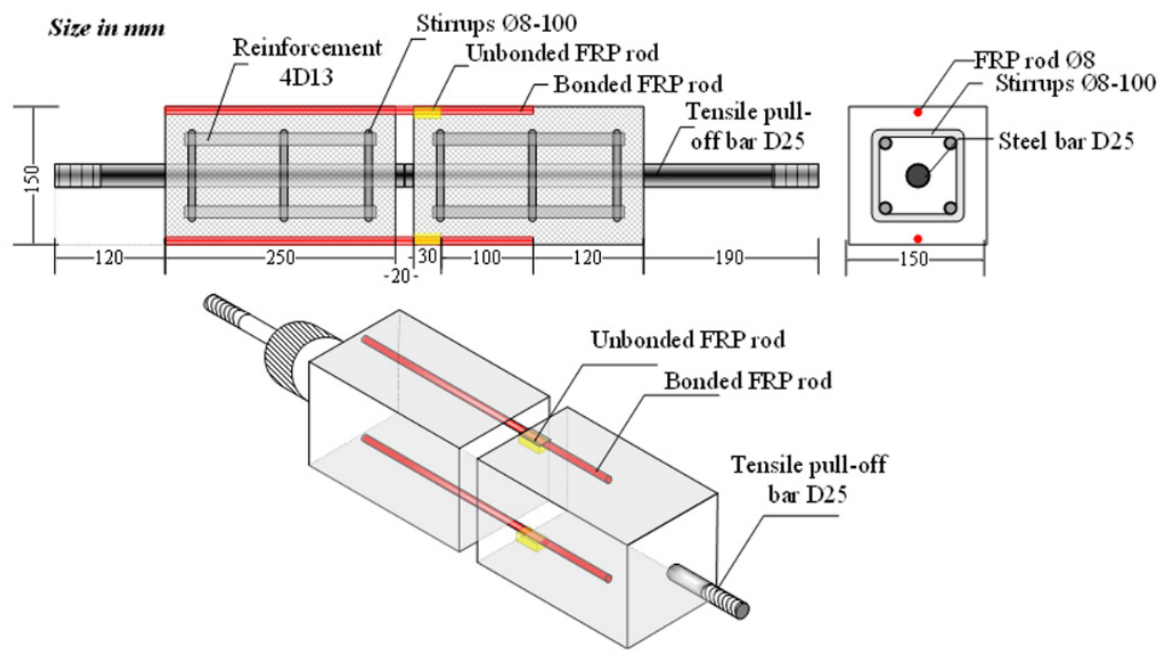

Fig. 3. Specimen assemblage of FRP rods testing [3].

This improved set-up system generated in much better results when compared to the previous method. This was observed from the behavior of the concrete blocks that did not show any indication of twisting. The standard deviations for the obtained data were also far below the values recorded during the FRP sheets experiment. The UTM applied a constant load increment of $20 \mathrm{~N} / \mathrm{sec}$. The experiments were terminated when the failure occurred. The concrete cylindrical compression strength was $36 \mathrm{MPa}$. Fig. 4 shows both the experimental set-up and the specimens at failure.

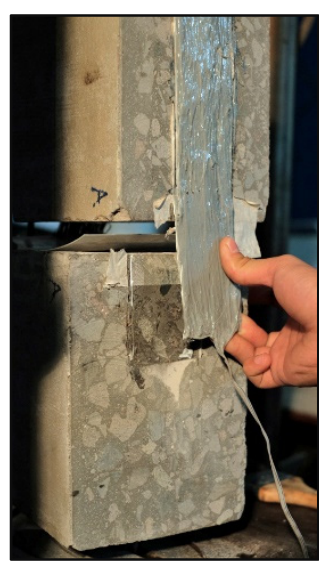

(a) FRP sheet failure

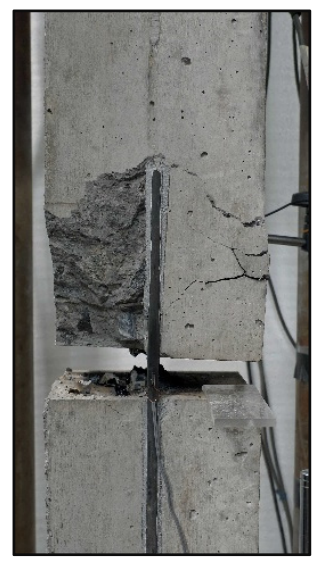

(b) FRP Rod failure

Fig. 4. Test set up and concrete failure for FRP sheets and rods.

\section{Bond strength and failure modes}

For the FRP sheets, two variables were studied: the surface treatment method and the number of plies [4]. As for the $8 \mathrm{~mm}$ rods, a variation in embedment-depth was investigated [3]. Three embedded depths were set at $14 \mathrm{~mm}, 10 \mathrm{~mm}$ and $6 \mathrm{~mm}$. The latest had only one-half of the rod planted into the concrete. Since the concrete compression strengths of the two tests 
differ, a modification method was conducted to convert the FRP sheet's results to the FRP rod test data.

For both the FRP reinforcements, two failure modes distinguished the stress at ultimate: debonding and concrete tension-shear [9]. For the FRP sheets, debonding occurred in the interface between the epoxy and the concrete and was detected only in the manufactureadvise-treated surfaces. The stresses were measured to be $3.3 \mathrm{MPa}$. For the FRP rods, debonding took place in the contact area between the rod and the epoxy resin. The stress values ranged from 16.1 MPa to 17.5 MP. Debonding for the FRP rods only occurred for the $6 \mathrm{~mm}$ embedment-depth specimens.

The concrete stress in tension-shear failure for the FRP sheets was calculated to be 5.3 $\mathrm{MPa}$, while the rods resulted in concrete stresses ranging from $2.3 \mathrm{MPa}$ to $2.8 \mathrm{MPa}$ as a function of rod embedment-depth. The increase in concrete tension-shear stress followed a parabolic path, as a direct function of the embedment-depth. The stresses, however, were substantially lower than the values obtained from the FRP sheets. The predicted concrete tension-shear strength based on the ACI code [10] was 4.8 MPa. It was also seen that the sheets induced a much smaller fracture area when compared to the rods (Figs. 5 and 6). The vertical fracture angle $\alpha$ for the sheets was measured to be only around $5^{\circ}$, while the rod resulted in a $24^{\circ}$ angle. The fracture angle in the horizontal plane $\theta$ was $2^{\circ}$ for the sheets, and $60^{\circ}$ for the rods. Combining these data with the bond length, the resulting fracture plane was much more confined for the sheets.

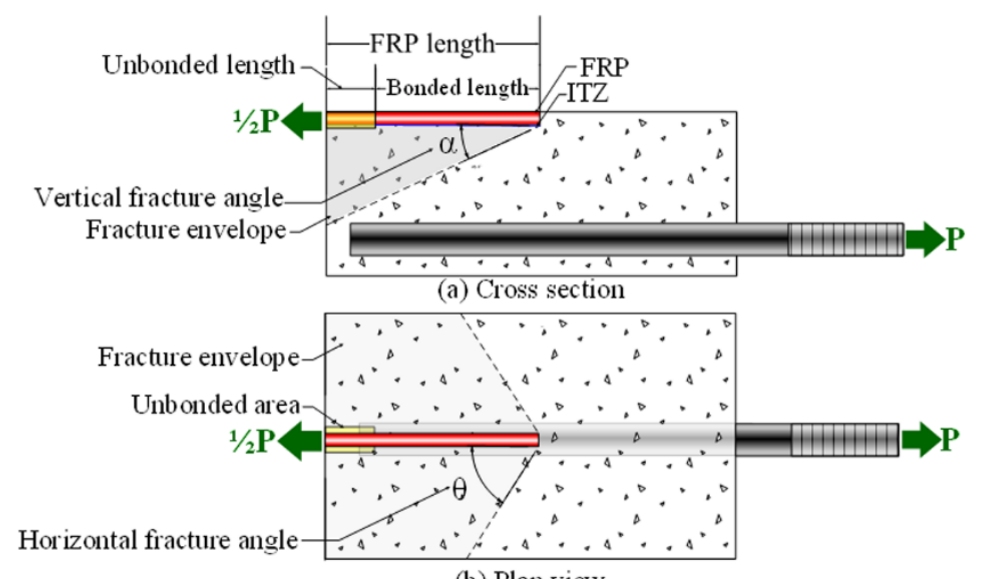

(b) Plan view

Fig. 5. Concrete fracture mechanism.

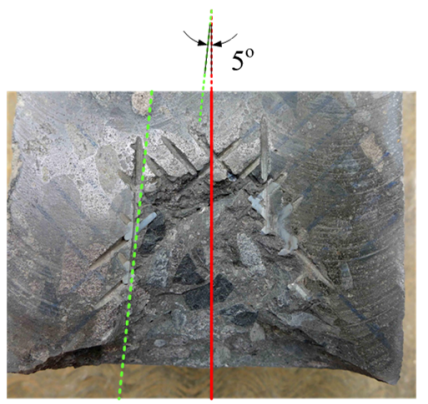

(a) FRP sheet

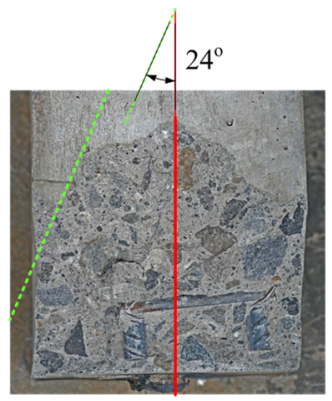

(b) FRP rod

Fig. 6. Concrete horizontal fracture angles. 
Figure 7 represents the stress levels as a function of the mode of failure. The concrete tension-shear strength as calculated based on the ACI formulations [10] is added for comparison purposes.

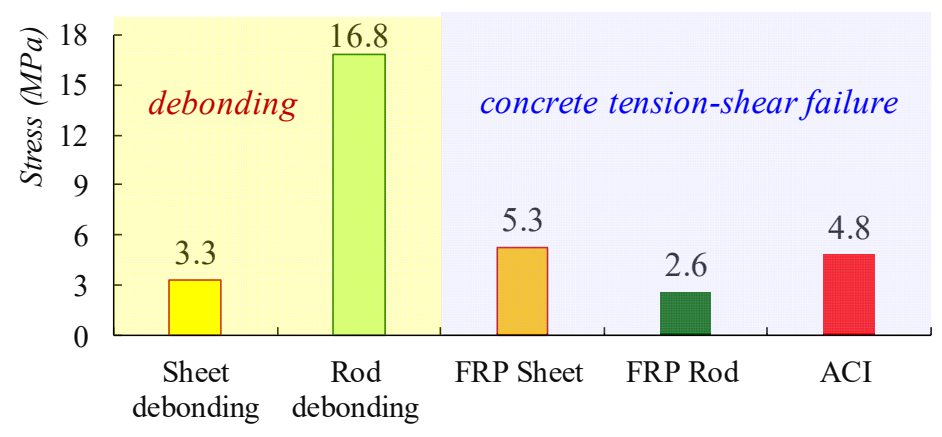

Failure mode

Fig. 7. Stresses at the ultimate.

\section{Data compilation and analyses}

From the study, it can be seen that the rods provide a better bond with the concrete. The horizontal and vertical fracture angles were significantly larger than those measured for the sheets, resulting in a much greater fracture area in the concrete. This large area in turn explains the low stresses induced by the FRP rods, reaching only $50 \%$ to the stresses for the FRP sheets, upon failure. A better bond is generally favored more in concrete since it will guarantee a better compatibility performance for the member in bending. The stress at the failure, however, was far below the predicted value based on the ACI formulas. The deeper the embedment of the rods into the concrete, the higher the stresses in the concrete upon failure. A better bond for the rods is acquired particularly from the nature of the rods that are solid, massive, homogeneous, and with a considerably higher material stiffness as compared to the sheets $[11,12,13]$. The FRP sheet is a composite of single FRP sheets and resin. Together the woven nature of the sheets resulted in a nonhomogeneous material, prone to stress concentrations. The FRP rod also has a better surface roughness, creating a better bond with the concrete and the epoxy agent.

From the test results, it was observed that the stresses in the ITZ for the rod are five times higher than the stresses at failure for the sheets. In all cases, the surface conditions of either the rod or the concrete, and the size of the bond area, played a key role in shifting the debonding failure mode to fracture of concrete.

\section{Conclusion}

The condition of the contact area between the external FRP reinforcement and the concrete influences the mode of failure for members in flexure. When using FRP sheets, the surface requires additional treatment, beyond the methods advised by the FRP producers. Cases of debonding on full-scale members were reported even though the surface was treated prior to sheet attachment. From these cases, it can be concluded that FRP sheets are very sensitive to the application methods of the sheets [14].

As for the rods, a one-half embedment-depth is insufficient to ensure that debonding will not occur in the member. This type of application should be avoided in practice, even when the concrete cover is limited, or stirrups are preventing the use of a larger depth. For the FRP rods, a 1.25-rod diameter embedment-depth is the minimum to guarantee concrete fracture 
[15]. The second factor, the influence of the bond area, is substantiated by these findings. One method to increase the bond strength for FRP sheets is thus by using a wider contact area, resulting in an increase in FRP sheets and resin consumption [16].

The codes need to be re-evaluated to accommodate the bond behavior and formulas of FRP elements since the test suggested that the ACI code underestimates the concrete tensileshear strength for FRP sheets but overestimates the stresses for FRP rods.

The rods are generally more practical because there are only small areas of the concrete subjected to grinding. One $8 \mathrm{~mm}$ rod resulted in the same capacity increase as $200 \mathrm{~mm}$ wide FRP sheets [14]. The grinding and surface treatment required for sheets also produces dust that pollutes the air and generates noise disturbances, while the rod only necessitates a 12 by $10 \mathrm{~mm}$ depth groove. Regarding epoxy resin used, the rods consume far less material than the sheets, which not only need one layer of resin to attach the sheet to the concrete, but has to be treated for every ply, including the upper surface of the sheets.

\section{References}

1. L. R. Taerwe, and S. Matthys, Concrete International, 21(10), 33-36, (1999)

2. C. W. Dolan, FRP Prestressing in the U.S.A., Concrete International, 21(10), 21-24, (1999)

3. A. Budipriyanto, A. L. Han, H. T. Hu, Accepted at Advanced Civil and Environmental Engineering, 1, (2018)

4. S. Tudjono, A. L. Han, A. Hidayat, Purwanto, Procedia Engineering, 171, 1116-1122, (2017)

5. M. Baena, L. Torres, A. Turon, C. Barris, Composites: Bart B, 40, 784-797, (2009)

6. R. Aghlara, R. Abdullah, M. M. Tahir, Journal of Applied Science, 12(21), 2235-2243, (2012)

7. G. Barbieri, L. Biolzi, M. Bocciarelli, S. Cattaneo, Composite Structures, 143, 395-417, (2016)

8. L. Biolzi, C. Ghittoni, R. Fedele, G. Rosati, Construction and Building Materials, 41, 182-190, (2013)

9. M. Ali-Akhmad, K. Subramaniam, M. Ghosn, Journal of Engineering Mechanics, 132(9), 914-923, (2006)

10. ACI 440.2R-08, Guide for the Design and Construction of Externally Bonded FRP Systems for Strengthening Concrete Structures. American Concrete Institute, Farmington Hills, (2008)

11. Gicquel, Y., Hamelin, P., Ferrier, E., Test Report Laboratoire Mécanique Matériaux et Structures. No. SIKA/06/01 du 04/05/06, Universite Lyon I, France, (2006)

12. F. Al-mahmou, A. Castel, R. Francois, C. C. Tourneur, Cement and Concrete Composites, 29, 677-689, (2007)

13. Product data sheet Sika Carbodur BC rods and SikaWrap 231 C, (2017)

14. SIKA research team, Technical Report on the use of FRP sheets and rods for T-section members in Bending, in Indonesian, Material and Structural Laboratory, Diponegoro University, (2018)

15. M. Caro, Y. Jemaa, S. Dirar, A. Quinn, Engineering Structures, 147, 448-457, (2017)

16. H. Toutanji, G. Ortiz, Composite Structures, 53(4), 457-462, (2001) 